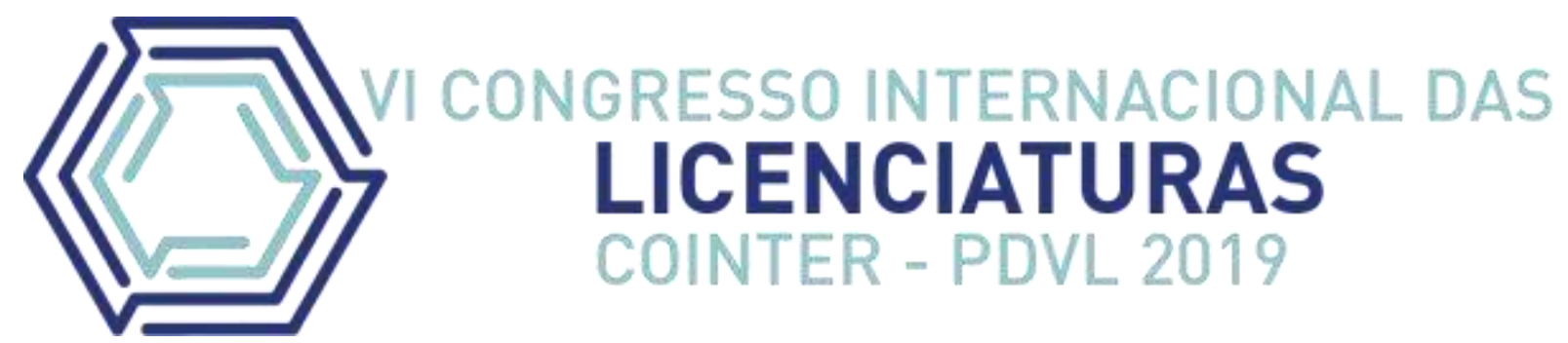

\title{
COMO SITES EDUCATIVOS ABORDAM A AGROECOLOGIA NO ENSINO DA GEOGRAFIA
}

\section{CÓMO LOS SITIOS EDUCATIVOS TRABAJAM LA AGROECOLOGÍA EM LA ENSEÑAZA DE LA GEOGRAFÍA}

\author{
Apresentação: Comunicação Oral \\ Wallace Matheus Aquino de Santana ${ }^{1}$; Joyce Barbosa Siqueira da Silva ${ }^{2}$; Jederson da Silva \\ Rocha $^{3}$; Ana Paula Torres de Queiroz ${ }^{4}$; Lúcia Ferreira Lirbório ${ }^{5}$ \\ DOI: https://doi.org/10.31692/2358-9728.VICOINTERPDVL.2019.0032
}

\begin{abstract}
Resumo
O presente trabalho visa compreender como os sites educativos trabalham a agroecologia e como eles podem ser utilizados na Geografia escolar. $\mathrm{O}$ interesse em discutir essa temática reside em entender como uma ferramenta tão atual pode auxiliar os estudantes a compreenderem melhor a agricultura em uma perspectiva ecológicas. Sabe-se que na atualidade as novas tecnologias vêm trazendo novas práticas e, assim conduzindo uma moderna administração do conhecimento, porém é necessário que os professores trabalhem com criatividade, pois sem métodos novos qualquer meio tecnológico continuará reproduzindo as metodologias tradicionais que priorizam a memorização. A pesquisa ocorreu primeiramente a partir de uma revisão bibliográfica sobre a temática abordada, após isso, fizemos análise de três diferentes sites que foram: Brasil Escola, Infoescola e o Portal Educação, a escolha desses portais é devido eles serem muito acessados pelos estudantes em pesquisas escolares. Sistematizamos as informações e redigimos o presente trabalho. Acreditamos que o site pode ser uma ferramenta bastante útil para os discentes, pois facilitam o aprendizado do estudantes sobre a agroecologia, trazendo essa reflexão ambiental na agricultura, porém acreditamos que essa temática devem ser abordadas não só na ciências naturais como química e biologia, também deve ser trabalhado na geografia, apresentado a relação desse tema com essa ciência. Concluímos que a maioria dos sites apresentam um reflexão da importância da relação da agricultura com a ecologia e além do conteúdos serem trabalhados em outras matérias, os docentes podem aproveitar diversas informações para suas aulas e para que os estudantes possam fazer sua pesquisa, tendo em vista uma visão da importância da relação de um setor

\footnotetext{
1 Licenciatura em Geografia, Instituto Federal de Educação, Ciência e Tecnologia de Pernambuco, wallace.aquino0@gmail.com

${ }^{2}$ Licenciatura em Geografia, Instituto Federal de Educação, Ciência e Tecnologia de Pernambuco, jupirak0@gmail.com

3 Licenciatura em Geografia, Instituto Federal de Educação, Ciência e Tecnologia de Pernambuco, jedersonsocha@hotmail.com

${ }^{4}$ Mestre, Docente do IFPE, anaqueiroz@ recife.ifpe.edu.br

${ }_{5}^{5}$ Doutora, Docente do IFPE, lucia.lirborio@belojardim.ifpe.edu.br
} 
econômico bastante importante da economia nacional com o meio-ambiente.

Palavras-Chave: Agroecologia, Geografia, Tecnologia

\begin{abstract}
Resumen
Este documento tiene como objetivo comprender cómo funcionan los sitios educativos sobre agroecología y cómo se pueden utilizar en la geografía escolar. El interés en discutir este tema radica en comprender cómo una herramienta tan actual puede ayudar a los estudiantes a comprender mejor la agricultura desde una perspectiva ecológica. Se sabe que hoy en día las nuevas tecnologías están aportando nuevas prácticas y, por lo tanto, liderando una gestión del conocimiento moderna, pero los maestros deben trabajar de manera creativa, porque sin nuevos métodos, cualquier medio tecnológico continuará reproduciendo las metodologías tradicionales que priorizan la memorización. La investigación se llevó a cabo principalmente a partir de una revisión bibliográfica sobre el tema abordado, después de eso, hicimos un análisis de tres sitios diferentes que fueron: Brasil Escola, Infoescola y el Portal de Educación, la elección de estos portales se debe a que son ampliamente accesibles por los estudiantes en investigación. escuela Sistematizamos la información y escribimos el presente trabajo. Creemos que el sitio puede ser una herramienta muy útil para los estudiantes, ya que facilita el aprendizaje de los estudiantes sobre la agroecología, trayendo esta reflexión ambiental en la agricultura, pero creemos que este tema debe abordarse no solo en las ciencias naturales como la química y la biología. Se debe trabajar en geografía, presentando la relación de este tema con esta ciencia. Llegamos a la conclusión de que la mayoría de los sitios reflejan la importancia de la relación entre agricultura y ecología y, además del contenido que se está trabajando en otras materias, los maestros pueden aprovechar la información diversa para sus clases y para que los estudiantes puedan hacer su investigación para Una visión de la importancia de la relación de un sector económico muy importante de la economía nacional con el medio ambiente.
\end{abstract}

Palabra clave: Agroecología, Geografía, Tecnología

\title{
Introdução
}

O presente trabalho visa compreender como os sites educativos trabalham a agroecologia e como eles podem ser utilizados na Geografia escolar. O interesse em discutir essa temática reside em entender como uma ferramenta tão atual pode auxiliar os estudantes a compreenderem melhor a agricultura em uma perspectiva ecológicas. As Novas Tecnologias da Informação e Comunicação (NTIC) estão cada vez mais inseridas no cotidiano das pessoas, seja em diferentes áreas e espaços, principalmente na educação, já que elas aproximam o educando ao conteúdo aplicado na escola e por ser uma ferramenta de grande empatia pelos os discentes. Segundo Silva (2001). O impacto das tecnologias da informação e comunicação na educação é, na verdade, um aspecto particular de um fenômeno muito mais amplo, relacionado com o papel dessas tecnologias na sociedade (COLL; MONEREO,2010, p.15). Sabe-se que na atualidade as novas tecnologias vêm trazendo novas práticas e, assim conduzindo uma moderna 
administração do conhecimento, porém é necessário que os professores trabalhem com criatividade, pois sem métodos novos qualquer meio tecnológico continuará reproduzindo as metodologias tradicionais que priorizam a memorização, reproduzindo velhos erros. A utilização de sites em sala de aula ainda é uma grande barreira, pois muitas escolas não oferecem estrutura adequada, seja por não dispor de boa conexão de internet, por contar com poucas NTIC ou pela falta de professores capacitados para trabalhar e incentivar os educandos a buscar mais informações a partir desse meio, Segundo Silva:

O impacto das transformações de nosso tempo obriga a sociedade, e mais especificamente os educadores, a repensarem a escola, a repensarem a sua temporalidade. E continua. Vale dizer que precisamos estar atentos para a urgência do tempo e reconhecer que a expansão das vias do saber não obedece mais a lógica vetorial. É necessário pensarmos a educação como um caleidoscópio, e perceberás múltiplas possibilidades que ela pode nos apresentar, os diversos olhares que ela impõe, sem, contudo, submetê-la à tirania do efêmero. (SILVA, 2001, p.37).

A escola tem o papel de formar cidadãos críticos, que possam compreender, por exemplo, o malefício da produção e do consumo de produtos agrícolas que utilizam em excesso agrotóxicos, pesticidas e uma gama de produtos utilizados na agricultura convencional, além dos produtos transgênicos. Mais recentemente as escolas tem incluído em seu currículo aulas que trabalhem os benefícios da produção orgânica e agroecológicas e a Geografia é uma das disciplinas em que essa temática pode ser discutida com os educandos.

A inclusão de alguns sites , poderá auxiliar o discente a se conectar com o conteúdo a compartilhar as informações, dessa forma deixando as pessoas do seu ciclo social cientes em saber que tipo de produto está consumindo, provocando as mudanças nos seus hábitos alimentares para uma saúde melhor, pela preservação ambiental ou pela preocupação com a relação do trabalho do agricultor. Porém para que isso tudo funcione tem que se fazer uma análise de qual site é mais adequado para que os estudantes compreendam melhor sobre a temática, então é necessário que o docente faça inicialmente uma análise, para depois indicar na aula a utilização desses recursos tecnológicos

O objetivo geral da pesquisa é identificar como alguns sites educativos trabalham sobre a agroecologia. Os objetivos específicos são verificar se eles estão trabalhando esses conteúdos na disciplina de Geografia, analisar e comparar a abordagem desse conteúdo em diferentes sites e identificar a formação dos autores que publicaram aquelas informações. Nesse sentido analisar a forma como esses meios trabalham agroecologia é essencial para compreendermos 
as dinâmicas recentes do espaço agrário brasileiro e mundial no que se refere às práticas agroecológicas e, seus rebatimentos para a sociedade são tratados.

\section{Fundamentação Teórica}

A agroecologia é uma das alternativas para a mudança do quadro de crise ambiental, tanto no Brasil como no mundo, por um modelo sustentável, pois ela é constituída de diversos conhecimentos em técnicas tradicionais "que incorporam princípios ecológicos e valores culturais às práticas agrícolas que, com o tempo, foram desecologizadas e desculturalizadas pela capitalização e tecnificação da agricultura" (LEFF, 2002, p. 42).

Com isso ela não dispensa os conhecimentos gerados por outras ciências buscando se integrar desses conhecimentos "Agroecologia é considerada como campo de conhecimento transdisciplinar, que recebe as influências das ciências sociais, naturais e agrárias" (EMBRAPA, 2016, p. 26).

Para Gliesmann (2001), a agroecologia busca uma agricultura sustentável que não libere substâncias tóxicas que não contaminem a atmosfera, a água e o solo, preservando a fertilidade do solo, prevenindo de erosões, favorecendo ele com nutrientes orgânicos e valorizando a conservação da biodiversidade.

Segundo Guzmán (2002), a agroecologia não é uma ciência, pois incorpora um conhecimento tradicional que não é um conhecimento científico. porém acreditamos que a agroecologia é uma ciência em construção.

$\mathrm{Na}$ atualidade percebemos que os modelos de produções convencionais e as produções transgênicas crescem em ritmo acelerado no Brasil. A agricultura convencional é caracterizada pela a utilização de agrotóxicos, fertilizantes e adubos químicos que prejudicam os recursos naturais como o solo, os rios e o ar, além de provocar problemas de saúde aos consumidores e aos agricultores que não utilizam as medidas de segurança necessárias para o cultivo desse tipo de produto.

Desde 2008, o Brasil ocupa o lugar de maior consumidor de agrotóxicos do mundo. Os impactos na saúde pública são amplos, atingem vastos territórios e envolvem diferentes grupos populacionais, como trabalhadores em diversos ramos de atividades, moradores do entorno de fábricas e fazendas, além de todos nós, que consumimos alimentos contaminados. (Dossiê Abrasco, 2015, p.39) 
Além do modelo de produção abordado acima, que tanto afeta a saúde e o meio ambiente, o cultivo de transgênicos, que são plantas ou sementes modificadas geneticamente, para a adaptação para diferentes tipos de clima e solo, vêm crescendo em ritmo acelerado Dessa forma alcança grande número de consumidores que tem como resultado um avanço em um ritmo acelerado desse tipo de produção no território brasileiro, levando nossa nação a ser a segunda maior produtora de produtos geneticamente modificados..

Para conter isso, novas técnicas agrícolas sustentáveis vêm sendo criadas para dar uma qualidade melhor aos produtos, oferecendo aos seus consumidores um produto saudável, que não afete o meio ambiente e valorize a relação de trabalho do agricultor, se diferenciando dos outros tipos de produção que não se preocupam com esses fatores.

O termo agricultura sustentável surgiu em 1980, como uma crítica aos métodos produtivos do modelo convencional, que cresceu aceleradamente acarretando um custo mais barato de transportes e vendas, mas com a utilização de agrotóxico, fertilizantes e adubos químicos provocando contaminações nos recursos hídricos, degradação do solo, morte de agentes polinizadores e contaminação do ar.

O conceito de agricultura sustentável surgiu na década de 1980, em resposta às técnicas e métodos empregados na agricultura convencional, que ao longo dos últimos anos permitiu aumentar a produção mundial de alimentos e diminuiu custos de plantio, transporte e comercialização. No entanto, este tipo de agricultura também provocou a degradação do solo e a perda da biodiversidade, com a prática da monocultura e o uso indiscriminado de fertilizantes e agrotóxicos. (KAMIYAMA, 2011, p.5)

Atualmente a indústria vem conseguido se envolver nas atividades agrícolas, adquirindo tudo que concebe lucro aos agricultores, provocando a eles vários riscos como a má colheita ocasionada pelo mau tempo e a grande dependência dos produtos agrícolas, que são obtidos a valores elevados, porém que acarreta na diminuição de preços da produção.

A indústria tem conseguido sucessivamente se apropriar de uma parte crescente das atividades dos agricultores, tomando deles tudo o que gera lucros seguros, deixando-lhes diversos riscos, entre os quais o de má colheita devido a mau tempo e o risco de perder dinheiro devido à crescente dependência de insumos agrícolas, adquiridos a preços cada vez mais altos e tendo que vender seus produtos a preços cada vez mais baixos. (Lutzemberger, 2001, p.61) 
A agroecologia busca compreender as bases ecológicas fundamentados na produção agrícola tradicional, dessa forma desenvolvendo uma agricultura moderna e sustentável, já no paradigma tradicional busca difundir as tecnologias validadas.

\begin{abstract}
A agroecologia se fundamenta em uma base epistemológica distinta dos princípios da tradicional ciência ocidental. O paradigma agronômico tradicional considera o desenvolvimento da agricultura e dos agricultores a partir da difusão de tecnologias cientificamente validadas. O paradigma agroecológico procura entender as bases ecológicas que fundamentam os sistemas agrícolas tradicionais para, a partir daí, desenvolver uma agricultura moderna mais sustentável. (Norgaard, 1989, p.47)
\end{abstract}

No Brasil, a agroecologia é contemplada nas políticas públicas do Governo Federal, a partir do Plano Nacional de Agroecologia e Produção Orgânica - PLANAPO, contribuindo assim para o desenvolvimento sustentável, levando a população uma melhoria em sua qualidade de vida através da melhoria da oferta e o consumo de alimento mais saudáveis (BRASIL, 2013).

Segundo Demo, a base da educação escolar é a pesquisa, pois quem aprende é capaz de intervir de forma competente, crítica e inovadora: continuarão como massa de manobra e os sites podem auxiliar para essas pesquisas.

\footnotetext{
"Não é possível sair da condição de objeto (massa de manobra), sem formar consciência crítica desta situação e contestá-la com iniciativa própria, fazendo deste questionamento o caminho de mudança. Aí surge o sujeito, que o será tanto mais se, pela vida afora, andar sempre de olhos abertos, reconstruindose permanentemente pelo questionamento. Nesse horizonte, pesquisa e educação coincidem, ainda que, no todo, uma não possa reduzir- se à outra." (2007, p.8)
}

Muitas pessoas ainda desconhecem quais são as Novas Tecnologias da Informação e Comunicação. Na educação a primeira coisa que se pensa é no computador. No entanto, outros suportes também podem ser considerados tecnologias, já que eles são uma parte dos recursos tecnológicos que permitem o trânsito de informações, como por exemplo, o uso de data show, jornais impressos, revistas, televisores, etc. A tecnologia educacional engloba todos esses meios tecnológicos voltados ao ambiente escolar para que se possa ensinar e aprender.

Devemos saber que a quantidade de materiais tecnológicos que uma escola possui não significa que seja uma escola bem-sucedida, porque o que interessa é o domínio desses recursos pelos alunos e pelos professores. Segundo Moran (2001, p28), "Ensinar com novas tecnologias será uma revolução se mudarmos simultaneamente os paradigmas convencionais do ensino, que 
mantêm distantes professores e alunos. Caso contrário, conseguiremos dar um verniz de modernidade, sem mexer no essencial".

No ensino da Geografia, ainda prevalece na maioria das escolas, a forma tradicional, no qual prioriza a memorização do conteúdo que não é um método adequado, pois segundo Cavalcanti:

Mais do que conteúdos, é necessário também, ensinar-lhes modos de
pensamento e ação, ou seja, por meio de atividades proporcionadas nas aulas,
por meio do trabalho com conteúdos, os professores devem propiciar o
desenvolvimento de certas capacidades e habilidades (CAVALCANTI, 2012,
p. 34-35).

Ao trabalhar conteúdos geográficos com os seus educandos, o educador deve procurar estimular neles à curiosidade. Não adianta memorizar mecanicamente o conteúdo sem ter a liberdade de aventurar-se no mundo do conhecimento.

Práticas pedagógicas na Geografia escolar associadas à tecnologia de informação e comunicação ajudam estabelecer as relações entre o local e o global, inclusive despertando um interesse nos alunos, os quais fazem parte da Sociedade da Informação. Sendo assim, a Geografia deve se utilizar das tecnologias de comunicação e informação no intuito de tornar suas aulas mais dinâmicas e interessantes para promover no aluno o desejo de aprender o que possa vir a ser ensinado, uma vez que para alguns alunos a Geografia ainda é vista como uma disciplina de pouco prestígio. Em uma pesquisa, Cavalcanti revela que:

\footnotetext{
Os alunos da pesquisa, no geral, afirmam não gostar da Geografia estudada na escola. Pelos dados, $32 \%$ dos alunos declararam não gostar de Geografia e 10\% declararam gostar "mais ou menos". Além disso, outro dado relevante é o índice de rejeição pela matéria: $23 \%$ apontaram a Geografia como uma das três matérias que menos gostam (1998, p.129)
}

A referida autora acrescenta que "existem duas razões principais para não se gostar de Geografia na escola. Em primeiro lugar, há um descontentamento quanto ao modo de trabalhar a Geografia na escola. Em segundo, percebem-se as dificuldades de compreender a utilidade dos conteúdos trabalhados" (1998, p.130). Diante disso, o uso de práticas pedagógicas associadas à tecnologia de comunicação e informações pode auxiliar a prática do professor possibilitando uma nova didática para o processo ensino-aprendizagem da geografia escolar.

\section{Metodologia}


A pesquisa em questão se iniciou através de uma pesquisa bibliográfica que segundo Boccato (2006):

\begin{abstract}
A pesquisa bibliográfica busca a resolução de um problema (hipótese) por meio de referenciais teóricos publicados, analisando e discutindo as várias contribuições científicas. Esse tipo de pesquisa trará subsídios para o conhecimento sobre o que foi pesquisado, como e sob que enfoque e/ou perspectivas foi tratado o assunto apresentado na literatura científica. Para tanto, é de suma importância que o pesquisador realize um planejamento sistemático do processo de pesquisa, compreendendo desde a definição temática, passando pela construção lógica do trabalho até a decisão da sua forma de comunicação e divulgação. (Boccato, 2006, p.266)
\end{abstract}

Após isso, fizemos análise de três diferentes sites que foram: Brasil Escola, Infoescola e o Portal Educação, a escolha desses portais é devido eles serem muito acessados pelos estudantes em pesquisas escolares. Sistematizamos as informações e redigimos o presente trabalho.

\title{
Resultados e Discussões
}

Na pesquisa analisamos primeiramente em que disciplina está inserida a temática agroecologia nos sites abaixo:

Portal Brasil Escola - Biologia e Química

Infoescola - Biologia

Portal Educação - Biologia.

Posteriormente observamos a forma em que o conteúdo foi aplicado em cada site.

Brasil Escola - Na Biologia analisava a importância da agroecologia como um meio sustentável que pode substituir o modelo convencional, inicialmente explica o conceito explicado por diversos autores, faz uma crítica ao uso exagerado de agrotóxicos na produção agrícolas e abordava a importância desse modelo. Na Química inicialmente faz uma crítica ao uso exagerado de agrotóxicos, relata as péssimas condições de trabalho dos agricultores, as poluições geradas pela produção tradicional e a importância do Rio+20 para agricultura familiar. 
Infoescola - Apresentava o conceito da agroecologia, a importância do manejo orgânico, os graves ricos gerados pela produção e consumo de transgênicos e sobre a política nacional de agroecologia.

Portal Educação - Inicialmente faz uma crítica a degradação ambiental gerado pela produção convencional, a economia na agricultura convencional, os impactos dessa produção na sociedade, explica o agrossistema e a importância da agroecologia e o Sistema agroflorestal.

Em seguida analisamos a forma em que esse conteúdo está sendo abordado em cada portal.

Brasil Escola - Nas duas disciplinas possuíam uma linguagem apropriada para turma de ensino médio,

Infoescola - Linguagem apropriada para estudantes de ensino fundamental (anos finais) e médio

Portal Educação - Ensino Médio e superior

Por último analisamos que formação tem as pessoas que produziram o material

Brasil Escola - Biologia (Não Informado), Química (Graduada em Química bacharelado)

Infoescola - Licenciatura em Geografia

Portal Educação - Gestão Ambiental

Por último analisamos as atividades de acordo com a temática e que conteúdo e disciplinas elas estavam inseridas. 
Brasil Escola - Contava com algumas questões de agroecologia no conteúdo Agricultura e Conservação na disciplina de Geografia.

Infoescola - Não contava com nenhuma questão

Portal Educação - Não contava com nenhuma questão

A partir da primeira análise percebemos que muitos desses sites ainda não trabalham esses conteúdos na disciplina de Geografia, porém seria interessantes que eles fossem trabalhados pelos docentes dessa disciplina, Já que de acordo com a BNCC 2018, turmas de sextos anos do ensino fundamental anos finais tem como habilidade "(EF06GE06) Identificar as características das paisagens transformadas pelo trabalho humano a partir do desenvolvimento da agropecuária e do processo de industrialização.” (BNCC, 2018, p.385) nos sétimos anos "(EF07GE06) Discutir em que medida a produção, a circulação e o consumo de mercadorias provocam impactos ambientais, assim como influem na distribuição de riquezas, em diferentes lugares" (BNCC, 2018, p.387) e de nono anos "(EF09GE13) Analisar a importância da produção agropecuária na sociedade urbano-industrial ante o problema da desigualdade mundial de acesso aos recursos alimentares e à matéria-prima." (BNCC, 2018, p.393). Dessa forma é necessário que a agroecologia também ser trabalhadas nos conteúdos de Geografia a partir da visão da relação entre o homem e o meio.

Como nenhum portal trabalhou com a disciplina nas pesquisas, parte dos materiais podem ser trabalhado para as aulas de Geografia, a visão de cada conteúdo foram voltadas para as matérias em que estavam inseridos, porém também percebemos que esse tema vem se destacando nessas outras disciplinas em que o estudante ou o docente pode fazer uma interdisciplinaridades desse conteúdo. Percebemos também que as linguagens desses materiais devem se apropriar de uma linguagem voltadas aos jovens de fundamentais anos finais e ensino médio muito ainda utilizam muitos termos muito técnico.

O site Brasil Escola trabalhou o conteúdo apresentando uma visão mais ambiental abordando a importância do RIO+20 para agricultura familiar, o Infoescola trabalho de forma 
muito resumida, explorando pouco os conteúdos. O Portal Educação trabalhou diferentes técnicas agroecológica s como os Sistemas Agroflorestais (SAF’S),

$\mathrm{Na}$ questão dos autores percebemos que todos tiveram uma graduação diferenciada, porém o que chamou atenção é que a produção do conteúdo do Infoescola era feita por uma professora de Geografia, no qual ela poderia trabalhar esse conteúdo melhor nessa disciplina.

Acreditamos que o site pode ser uma ferramenta bastante útil para os discentes, pois facilitam o aprendizado do estudantes sobre a agroecologia, trazendo essa reflexão ambiental na agricultura, porém acreditamos que essa temática devem ser abordadas não só na ciências naturais como química e biologia, também deve ser trabalhado na geografia, apresentado a relação desse tema com essa ciência.

\section{Conclusões}

Concluímos que a maioria dos sites apresentam um reflexão da importância da relação da agricultura com a ecologia e além dos conteúdos serem trabalhados em outras matérias, os docentes podem aproveitar diversas informações para suas aulas e para que os estudantes possam fazer sua pesquisa, tendo em vista uma visão da importância da relação de um setor econômico bastante importante da economia nacional com o meio-ambiente.

A agroecologia precisa ser debatida nas escolas pois é uma ciência dedicada ao relacionamento de uma atividade produtiva com o meio-ambiente, trabalhando uma sustentabilidade ecológica, econômica, social e cultural.

Acreditamos que a tecnologia sozinha não é capaz de promover um bom desenvolvimento dos indivíduos. É preciso profissionais capacitados, salas equipadas e confortáveis, meios que forneçam o uso das tecnologias, entre outros. As ferramentas tecnológicas são de grande acréscimo no ensino geográfico, como já abordado, o que falta de fato é o início de seu uso com maior intensidade e propriedade.

A agroecologia está sempre na luta com a agricultura convencional para que possamos tem uma consciência crítica, oferecendo uma qualidade de vida para população com práticas e alternativas sustentáveis.

A Geografia deve aprimorar mais os estudos sobre a agroecologia, e os docentes devem trazer novas metodologias pra trabalhar esse conteúdo em sala de aula, enxergando as tecnologias como uma ferramenta para facilitar a compressão dessa temática. 


\section{Referências}

ALTIERI, M. A. Agroecologia: as bases científicas da agricultura alternativa. 2. ed.p 53.

ARROYO, Miguel Gonzalez, CALDART, Roseli Salete; MOLINA, Monica Castagna: Por uma Educação do Campo. Petrópolis. R.J. Vozes - 2004.

BOCCATO, V. R. C. Metodologia da pesquisa bibliográfica na área odontológica e o artigo científico como forma de comunicação. Rev. Odontol. Univ. Cidade São Paulo, São Paulo, v. 18 , n. 3, p. $265-274,2006$

BRASIL. Ministério da Educação. Secretaria da Educação Básica. Base nacional comum curricular. Brasília, DF, 2016.

BRASIL. Plano Nacional de Agroecologia e Produção Orgânica. 2013. Disponível em: http://www.mda.gov.br/portalmda/sites/default/files/ceazinepdf/ cartilha1t_PLANO_NACIONAL_DE_AGR-379811.pdf. Acesso em: 15 mar. 2015.

BRITO, Glaucia; PURIFICAÇÃO, Ivonélia. Educação e Novas Tecnologias. $2^{\mathrm{a}}$ ed. Curitiba: IBPEX, 2008

BUAINAIN, A. M. Agricultura Familiar, Agroecologia e Desenvolvimento Sustentável: questões para debate. Brasília: IICA, 2006.

CARVALHO, Horacio Martins de. Desafios para a agroecologia como portadora de uma nova matriz tecnológica para o campesinato. Texto inédito. Jul., 2007.

CARVALHO, N. D; SOUZA, M. M. O. Geografia e pesquisa quantitativa: nas trilhas da investigação. Org: Júlio César de Lima Ramires; Vera Lúcia Salazar Pessôa. - Uberlândia: Assis, 2009.

COSTA, P. C; GIANASI, L. M. Estudo de Agroecossistemas Agroecológicos no Semiárido Mineiro: as ferramentas do Diagnóstico Rural Participativo como método de 172 A contribuição da geografia agrária em pesquisa-ação e a produção de alimentos agroecológicos em comunidades rurais e quilombolas do vale do Jequitinhonha. Revista Geonordeste, São Cristóvão, Ano XXV, n. 2, Edição Especial, p. 155-172, Ago/2014 investigação. Resumos do VII Congresso de Agroecologia. Cadernos de Agroecologia. Vol. 6, No. 2. Fortaleza: 2011 CAVALCANTI, Lana de Sousa. Geografia, escola e construção do conhecimento. Campinas: Papirus, 1998.

Concepções de Geografia e de Geografia Escolar no Mundo Contemporâneo. IN: A Geografia Escolar e a Cidade: Ensaios sobre o Ensino de Geografia para a vida Urbana Cotidiana. $3^{\mathrm{a}}$ Edição. Campinas, SP: Papirus, 2012.

COLL, C.; MONEREO, C. Psicologia da Educação Virtual: Aprender e Ensinar com as Tecnologias da Informação e Comunicação. Tradução de Naila Freitas. Porto Alegre: Artmed, 2010. 
DEMO, Pedro. Educar Pela Pesquisa. 8 ed. Campinas: Autores Associados, 2007.

Dossiê ABRASCO: um alerta sobre os impactos dos agrotóxicos na saúde / Organização de Fernando Ferreira Carneiro, Lia Giraldo da Silva Augusto, Raquel Maria Rigotto, Karen Friedrich e André Campos Búrigo. - Rio de Janeiro: EPSJV; São Paulo: Expressão Popular, 2015.

EMBRAPA. Marco Referencial em Agroecologia. Brasília: Embrapa (Empresa Brasileira de Pesquisa Agropecuária), 2006, 70 p.

FREIRE, P. Pedagogia da autonomia: saberes necessários à prática educativa. Rio de Janeiro: Paz e Terra, 2001.

NOVA ESCOLA. "Grandes pensadores 41 educadores que fizeram história, da Grécia antiga aos dias de hoje". Revista Nova Escola. São Paulo: Editora Abril, Ed. Especial n 19, julho 2008 .

KAMIYAMA, A. Cadernos de Educação Ambiental: agricultura sustentável. São Paulo: SMA, 2011. Disponível em: http://www.ambiente.sp.gov.br/uploads/ arquivos/cadernos/13AgriculturaSustentavel.pdf. Acesso em: 12 mar. 2019

LEFF, E. Agroecologia e saber ambiental. Agroecologia e Desenvolvimento Rural Sustentável. v.3, n.1, p.36-51, 2002.

LÜDKE, Menga. “O professor, seu saber e sua pesquisa". In: Revista Educação \& Sociedade, ano XXII, $\mathrm{n}^{\circ}$ 74, abril/ 2001. Disponível em:< http://www.scielo.br/pdf/es/v22n74/a06v2274.pdf > Acessado em outubro de 2008.

GLIESSMANN, S. R. Agroecologia: processos ecológicos em agricultura sustentável. 2. ed. Porto Alegre: Universidade Federal do Rio Grande do Sul, 2001.

GUZMÁN, E. S. Agroecologia e desarrollo rural sustentable. In: CURSO INTENSIVO EM AGROECOLOGIA: PRINCÍPIOS E TECNICAS ECOLÓGICAS APLICADAS À AGRICULTURA, 11., 2002, Seropédica. Palestra... Seropédica: Embrapa Agrobiologia, 2002.

Lutzenberger, J. (2001). O absurdo da agricultura. Estudos Avançados, 15(43), 61-74. Recuperado de http://www.revistas.usp.br/eav/article/view/9823

MARTINS, Jorge Santos. O trabalho com projetos de pesquisa: do ensino fundamental ao ensino médio. 5 ed. Campinas, SP: Papirus, 2007.

NORGAARD, R. B. A base epistemológica da agroecologia. In: ALTIERI, M. A. (Ed.) Agroecologia: as bases científicas da agricultura alternativa. Rio de Janeiro: PTA/Fase, 1989. p.42-8.

Oliveira, Ariovaldo Umbelino. Agricultura camponesa no Brasil. São Paulo: Contexto, 1991. 
RAMIRES. J. C; PESSÔA, V. L. N. Geografia e pesquisa quantitativa: nas trilhas da investigação. Org: Júlio César de Lima Ramires; Vera Lúcia Salazar Pessôa. - Uberlândia: Assis, 2009.

Raffestin, Claude. Por Uma Geografia do Poder. São Paulo: Editora Ática, 1993

Salete Caldart, Roseli. EDUCAÇÃO DO CAMPO: NOTAS PARA UMA ANÁLISE DE PERCURSO Trabalho, Educação e Saúde, vol. 7, núm. 1, marzo-junio, 2009, pp. 35-64 Escola Politécnica de Saúde Joaquim Venâncio Rio de Janeiro, Brasil

SILVA, Mozart Linhares da. A urgência do tempo: novas tecnologias e educação contemporânea. In: (org.) Novas Tecnologias: educação e sociedade na era da informática. Belo Horizonte: Autêntica, 2001.

STEDILE, João Pedro. Subsídios para compreender o significado da crise alimentar mundial e brasileira. Texto inédito. Maio, 2008. 